\title{
Trends in Sales and Industry Perspectives of Package Sizes of Carbonates and Confectionery Products
}

\author{
Chloe Jensen ${ }^{\dagger}$, Kirsten Fang ${ }^{\dagger}$, Amanda Grech and Anna Rangan *D \\ Nutrition and Dietetics, School of Life and Environmental Sciences, Charles Perkins Centre, The University of \\ Sydney, Sydney, NSW 2006, Australia; cjen7207@uni.sydney.edu.au (C.J.); kfan0424@uni.sydney.edu.au (K.F.); \\ Amanda.grech@sydney.edu.au (A.G.) \\ * Correspondence: anna.rangan@sydney.edu.au \\ † Both authors contributed equally to this work.
}

check for updates

Citation: Jensen, C.; Fang, K.; Grech, A.; Rangan, A. Trends in Sales and Industry Perspectives of Package Sizes of Carbonates and Confectionery Products. Foods 2021 10, 1071. https://doi.org/10.3390/ foods10051071

Academic Editor: Bahar Aliakbarian

Received: 9 April 2021

Accepted: 7 May 2021

Published: 12 May 2021

Publisher's Note: MDPI stays neutral with regard to jurisdictional claims in published maps and institutional affiliations.

Copyright: (c) 2021 by the authors. Licensee MDPI, Basel, Switzerland. This article is an open access article distributed under the terms and conditions of the Creative Commons Attribution (CC BY) license (https:/ / creativecommons.org/licenses/by/ $4.0 /)$.
Abstract: Discretionary food package sizes are an important environmental cue that can affect the amount of food consumed. The aim of this study was to determine sales trends and reported food industry perspectives for changing food package sizes of carbonates and confectionery between 2005 and 2019. Changes in package sizes of carbonates and confectionery were investigated in Australia, the USA, Canada, and the UK. Sales data (units per capita and compound annual growth rate between 2005 and 2019) were extracted from the Euromonitor database. Qualitative data (market research reports) on industry perspectives on package size changes were extracted from industry and marketing databases. Carbonate sales data showed increased growth of smaller package sizes $(<300 \mathrm{~mL})$ and a decrease in sales of larger package sizes $(\geq 2000 \mathrm{~mL})$ in all four countries. In contrast, confectionery sales data showed no consistent trends across the selected countries. No growth was observed for smaller confectionery package sizes but an increase in growth of larger package sizes (50-99 g, >100 g), including share packages, was observed in Australia. Qualitative data ( $n=92$ articles) revealed key reasons identified by industry for changes in package size related to consumer health awareness, portion size control, convenience, market growth, and government or industry initiatives. Monitoring of discretionary food package sizes provides additional insights into consumers' food environment.

Keywords: package size; Euromonitor; carbonates; confectionery; monitoring; public health; food industry

\section{Introduction}

Over the past 30 years, portion sizes of many foods and beverages have increased, in particular nutrient-poor, energy-dense foods [1,2]. People consistently consume more food when offered larger sized portions, packages, or dishware (tableware) than when offered smaller-sized versions [3]. This 'portion size effect' has been observed in children and adults, males and females, and across those with different body weights, levels of dietary restraint, and susceptibility to hunger [3]. Snack foods and foods with a high energy density and/or low nutrient profile are particularly susceptible, likely due to their high palatability $[3,4]$. As there is little compensation in energy intake at subsequent meals, consuming larger portion sizes leads to higher energy intakes and increased risk of overweight and obesity [3,5].

The consumption of large portion sizes of energy-dense, nutrient-poor foods is particularly concerning [6,7]. In many countries, the consumption of such foods high in added sugar is excessive; for example, in Australia, sugar sweetened beverages (SSBs) and confectionery are leading contributors of added sugars and/or saturated fat intake [8]. Similarly, a 2010 report on American diet and health revealed that SSBs contributed 36\% of total added sugars and confectionery 6\% [9], and, in the UK, confectionery and SSBs were the main contributors to free sugar intake in adults in 2016 [10]. In Canada, SSBs were the 
main beverage contributor to energy intake in 2015 [11]. To reduce population intakes of these foods, targeting the portion and package sizes of these products has been proposed as a potential strategy. A Cochrane review [3] and other recent reviews [5,12-14] suggest that policies and practices that reduce the size, availability, and appeal of larger sized portions and packages can contribute to meaningful reductions in the quantities of food people select and consume immediately and in the short term. Environmental cues that promote the selection of smaller servings could be a valuable strategy to reduce portion sizes. Thus, a range of package sizes, with more options towards the lower end, is an important consideration to help redefine a new 'normal' [15-17] and guide consumers to reduce their energy intake at one occasion. Few studies have been conducted that examine the response of the food industry to the package sizes of discretionary foods.

The use of marketing databases such as Euromonitor International (Euromonitor) can provide valuable data and market research for changes in package sizes over time. The use of such databases has thus far been quite limited in public health nutrition research, likely due to the cost of access and publication restrictions. For this study we selected carbonates and confectionery as examples of packaged food products that are energy-dense, nutrient-poor, commonly consumed in high-income countries, available in a variety of package sizes, and well-defined as food product categories in Euromonitor. Four highincome countries-Australia, the United States of America (USA), Canada, and the United Kingdome (UK) — were chosen to compare and contrast any changes over time. It is a legal requirement that the net weight of the food is provided on all packaged foods in all four countries. Quantifying how package sizes of unhealthy food and beverages have changed over time helps to develop a better understanding of the food environment and how the food industry can influence the population's diet. Determining the principals that motivate industry to make changes to package sizes can assist in understanding the barriers and enablers that influence package size reduction and inflation. The aims of our study were firstly to examine the trends in sales of varying food package sizes over the last 15 years for carbonates and confectionery in four high-income countries and secondly to investigate the industry-reported reasons for these trends.

\section{Methods}

\subsection{Sales Trends According to Package Size: Carbonates and Confectionery}

Sales data for carbonates and confectionery were obtained for analysis from the Euromonitor Passport Global Market Information Database, 2019 Edition (Euromonitor). This market research database contains data from multiple primary and secondary sources, including company financial reports, store audits, official government statistics, and data from industry bodies [18]; however, the exact data sources for carbonates and confectionery are not available. 'Carbonates' include sweetened, non-alcoholic drinks containing carbon dioxide, both regular and low calorie and naturally and artificially sweetened, but exclude carbonated water, tea drinks, and energy drinks; while 'confectionery' includes chocolate confectionery, gum, and sugar confectionery. Sales data for units of packages (or packs) were obtained from 2005 to 2019 for four countries: Australia, the USA, Canada, and the UK. The search strategy is illustrated in Figure S1.

Sales data, including package unit sales and compound annual growth rate (CAGR), were exported from Euromonitor into Microsoft Excel for the years and countries of interest. Package unit sales for carbonates were classified as total sales and separately for retail and foodservice sales. Only retail sales were available for confectionery. Retail sales were defined as sales through establishments engaged in sales of goods, including supermarkets, convenience stores, department stores, and grocery retailers. Foodservice sales were defined as sales to foodservice establishments, such as restaurants, cafes, bars, fast food outlets, home delivery and takeaway services, self-service cafeterias, kiosks, and street stalls [18] (Table S2). The CAGR is defined as the annual average growth rate, expressed in percentage terms, for the selected forecast period. 
Sales data were organised according to package size and year, with package sizes placed into size bands and years placed into five-year bands to explore sales trends over time. Five package size bands were chosen for carbonates: $<300 \mathrm{~mL}, 300-399 \mathrm{~mL}$, 400-999 mL, 1000-1999 mL, and $\geq 2000 \mathrm{~mL}$, and four package size bands were chosen for confectionery: $<25$ g, 25-49 g, 50-99 g, and $\geq 100$ g. The five-year bands were 2005-2009, 2010-2014, and 2015-2019. Package unit sales (total and retail and foodservice sales where available) were summed according to package size and year band. The package unit sales data were converted to per capita sales using population statistics available on Euromonitor. All sales data were graphed by country for unit sales per capita for each five-year band and for the per capita CAGR between 2005 and 2019. Growth was considered as positive if there was $\geq+1 \%$ change; negative if there was $\geq-1 \%$ change; and stable if there was $<1 \%$ change over 15 years.

\subsection{Food Industry Perspectives on Package Size: Carbonates and Confectionery}

To document the food industry perspectives on package size changes over time, a systematic approach was adopted by applying the Preferred Reporting Items for Systematic Reviews and Meta-Analyses Extension for Scoping Reviews (PRISMA-ScR) guidelines [19].

Sources were considered eligible if they were articles such as market reports and trade publications, had a title or summary containing information on changes to package sizing for carbonates or confectionery, were obtained from Australia, the USA, Canada, or the UK, and were published between 2005 and 2020. Sources were excluded if changes in package sizes were not clearly described. Euromonitor, IBISWorld, and the internet search engine Google were searched. Access to Euromonitor was available from 2005-2020 and to IBISWorld from 2019-2020. IBISWorld is an industry market research database comprising reports written by expert analysts utilizing worldwide economic, demographic, and market data [20]. Google uses an authority-based algorithm that displays ranked results by relative importance depending on the linked domain.

The search strategy used to extract industry reports from the Euromonitor database is described in Figure S1. A systematic key word search to obtain additional qualitative data was performed on Euromonitor, IBISWorld, and Google (Table S1). The first 100 results from Google were analysed, as per Dumas et al. [21]. All searches were conducted on 16 April 2020. Two reviewers (C.J. and K.F.) independently sourced and assessed the eligibility of publications identified by the search strategies. The screening process involved title and abstract or introduction review followed by full text appraisal. Disagreements over inclusion or exclusion were resolved through discussion with a third party (A.G. and A.R.). A full list of sources and websites is available on request.

The extraction and charting of industry report data were performed in duplicate by two independent reviewers using a customised template designed for this study. Data items included country of report, year of publication, title, article type (e.g., opinion article, briefings), direction of change in package size (increase or decrease), specific changes in package size, and the reported reasons for the change. Any discrepancies in judgement were discussed and consensus reached on all occasions.

\section{Results}

\subsection{Sales Trends According to Package Size: Carbonates (Retail and Foodservice)}

Total per capita unit sales of carbonates were highest in the USA, followed by Canada, Australia, and the UK, between 2005 and 2019 (Figure 1), with the most popular package size being 300-399 mL in these countries. Total per capita unit sales decreased during this time period in Australia, the USA, and Canada but remained relatively stable in the UK. With regard to package sizes, positive growth (per capita CAGR) was shown for $<300 \mathrm{~mL}$ carbonates, while growth for $\geq 2000 \mathrm{~mL}$ carbonates decreased in all four countries between 2005 and 2019 (Figure 2). 

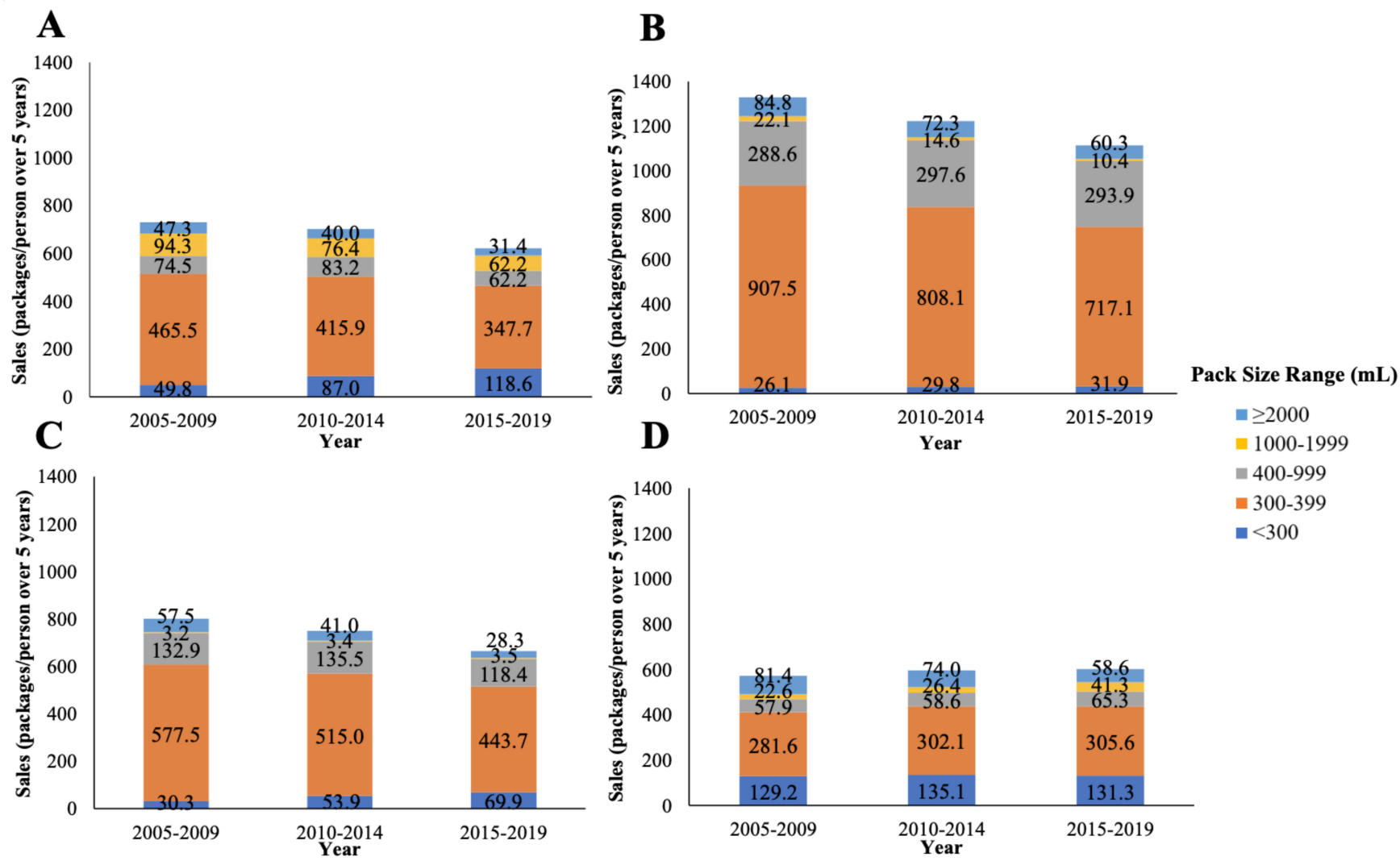

Figure 1. Total package sales per capita, including retail and foodservice sales, over five-year periods from 2005 to 2019 in carbonates according to package size band in (A) Australia, (B) the USA, (C) Canada, and (D) the UK.

For all countries, retail unit sales accounted for the largest proportion of total carbonate unit sales (70-92\%) and showed similar trends to total carbonate unit sales (Figure S2). Total foodservice unit sales decreased between 2005 and 2019 in Australia, Canada, and the UK for all package sizes. The most popular sizes in foodservice were $<300 \mathrm{~mL}$ in the UK, 300-399 mL in Australia and Canada, and 400-999 mL in the USA (Figure S3).

\subsection{Sales Trends According to Package Size: Confectionery (Retail Only)}

Per capita unit sales of confectionery were highest in the UK, followed by the USA, Canada, and Australia. Between 2005 and 2019, total per capita unit sales decreased in the USA, whereas unit sales remained relatively stable in Australia, Canada, and the UK (Figure 3). No consistent pattern was found in terms of unit sales of package sizes during this time across the four countries. Between 2005 and 2019, growth (per capita CAGR) of small package sizes $(<25$ and $25-49 \mathrm{~g})$ decreased or remained relatively stable in all countries (Figure 4). Growth of larger package sizes (50-99 $\mathrm{g}$ and $>100 \mathrm{~g}$ ) was observed in Australia but not in other countries where sales remained stable (USA and Canada) or decreased (UK). 

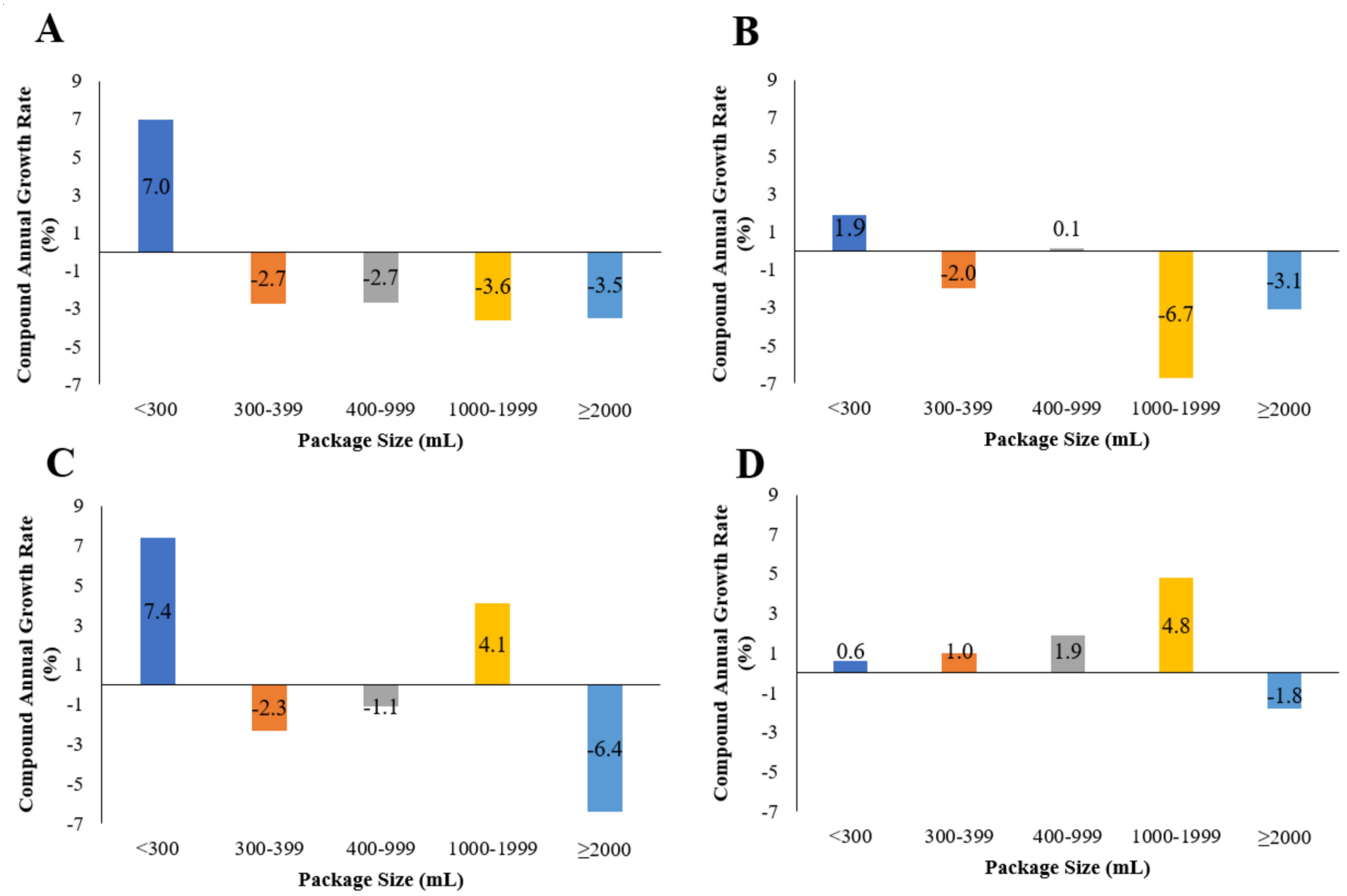

Figure 2. Compound annual growth rate of total package per capita sales, including retail and foodservice sales, of carbonates for 2005 to 2019 according to package size band in (A) Australia, (B) the USA, (C) Canada, and (D) the UK.

\subsection{Food Industry Perspectives on Package Size: Carbonates and Confectionery}

The initial search of the electronic databases identified 451 articles (market reports and trade publications) and, after removal of duplicates, resulted in 408 articles (Figure 5). Following screening of the titles and abstracts/introductions, a further 289 articles were excluded. Full texts were retrieved for 119 articles for detailed evaluation against the eligibility criteria and a total of 92 articles (carbonates, $n=51$; confectionery, $n=39$; and carbonates and confectionery, $n=2$ ) were included for qualitative synthesis. Articles came from a variety of sources, such as ConfectioneryNews.com, Forbes, Beveragedaily.com, Euromonitor research reports, and direct from company websites. Most of the included articles originated from the UK (particularly confectionery), the USA, or Australia with fewer from Canada. The majority of articles were published after 2013. 
A
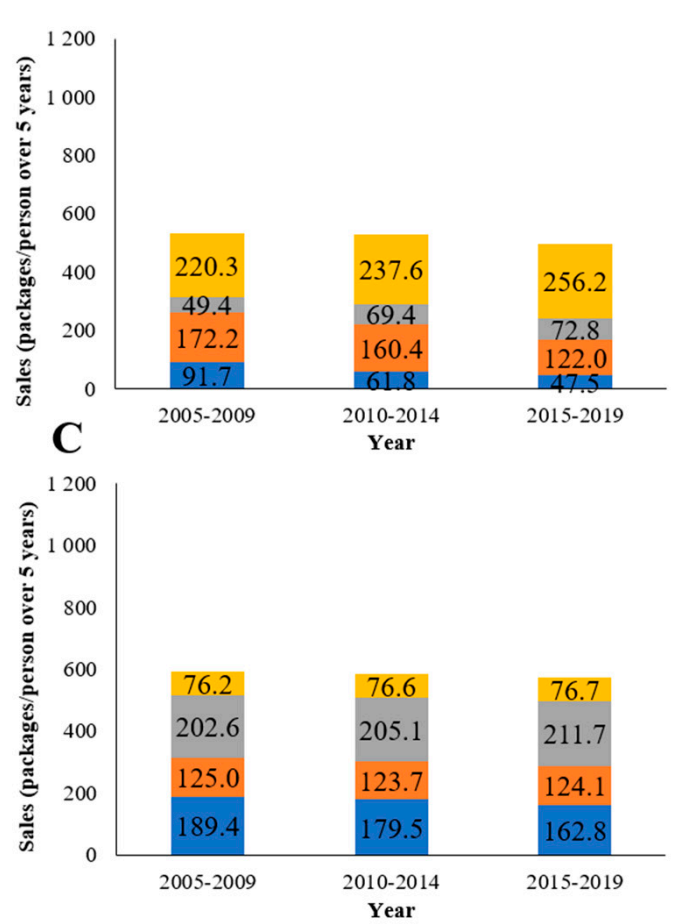

B
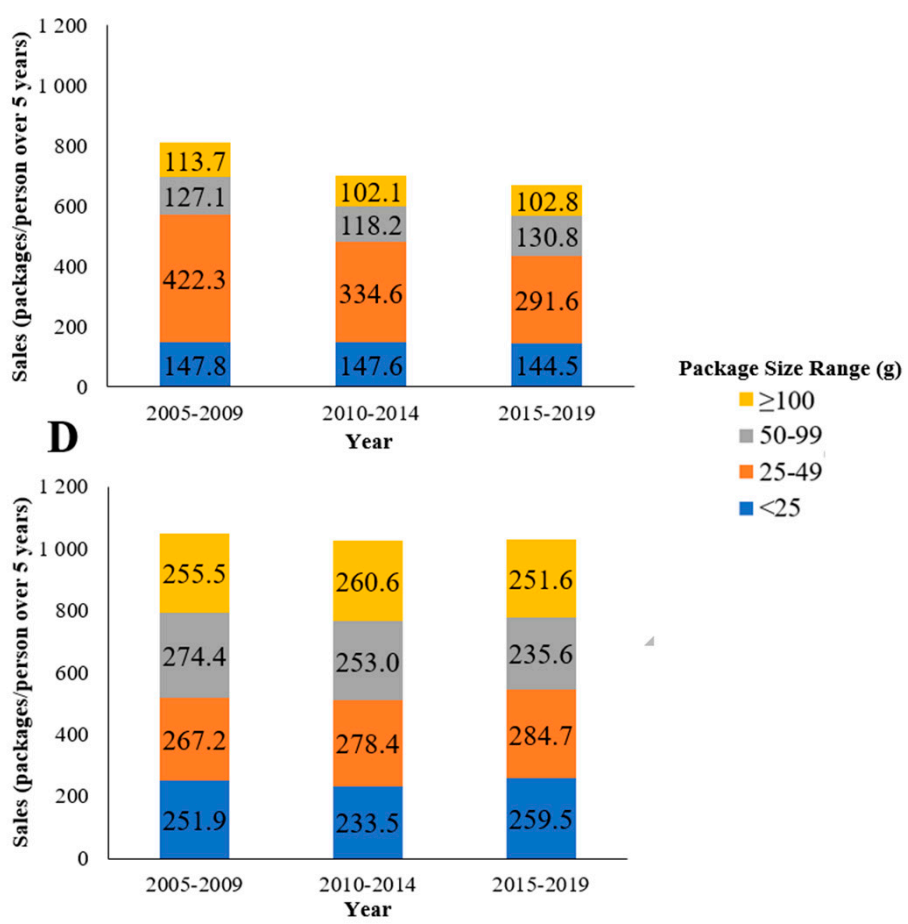

Figure 3. Total package sales in confectionery (retail only) per capita over five-year periods from 2005 to 2019 according to package size bands in (A) Australia, (B) the USA, (C) Canada, and (D) the UK.

A
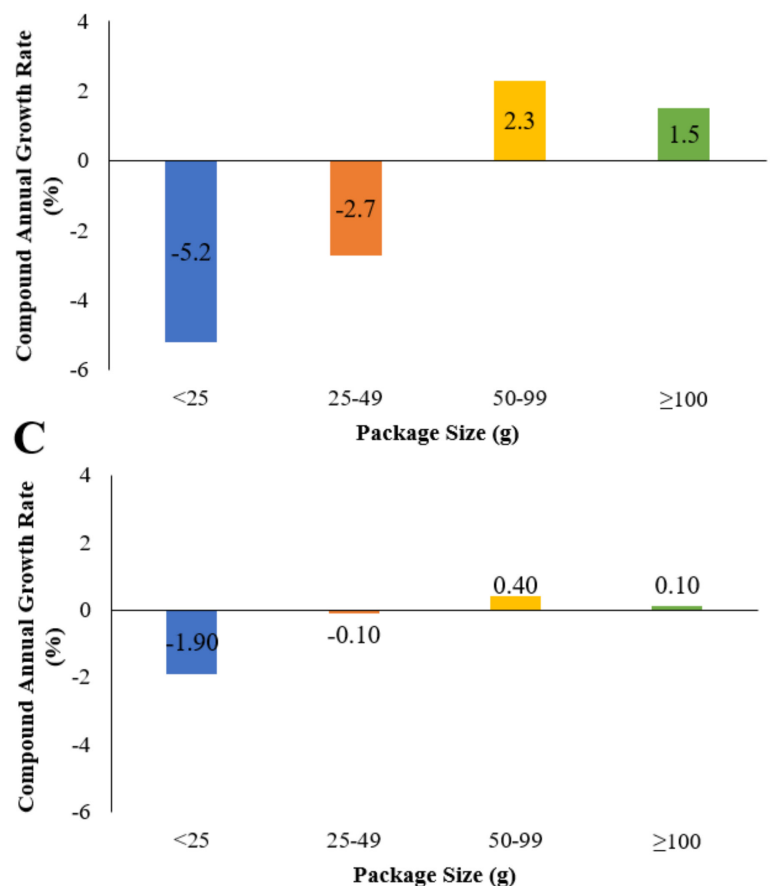

B

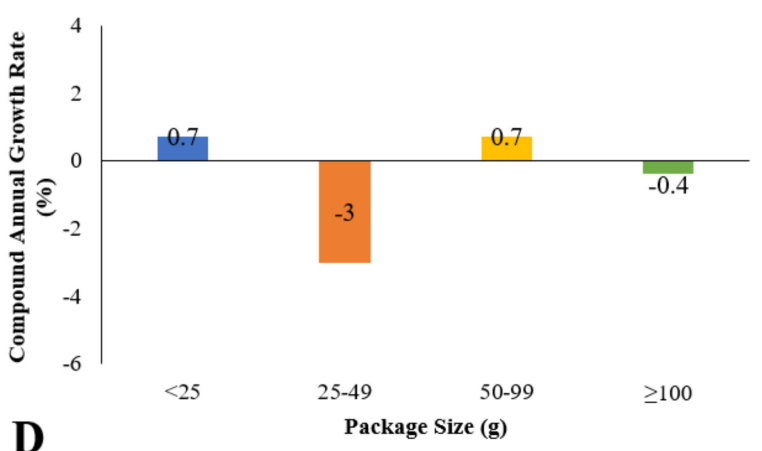

D

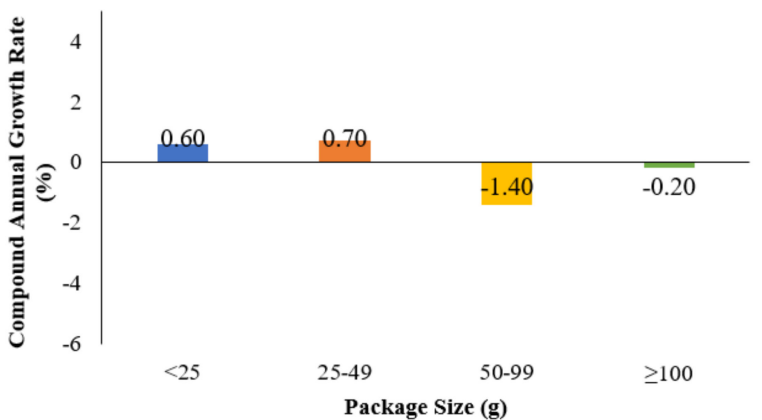

Figure 4. Compound annual growth rate of total package per capita sales of confectionery (retail only) for 2005 to 2019 according to package size band in (A) Australia, (B) the USA, (C) Canada, and (D) the UK. 


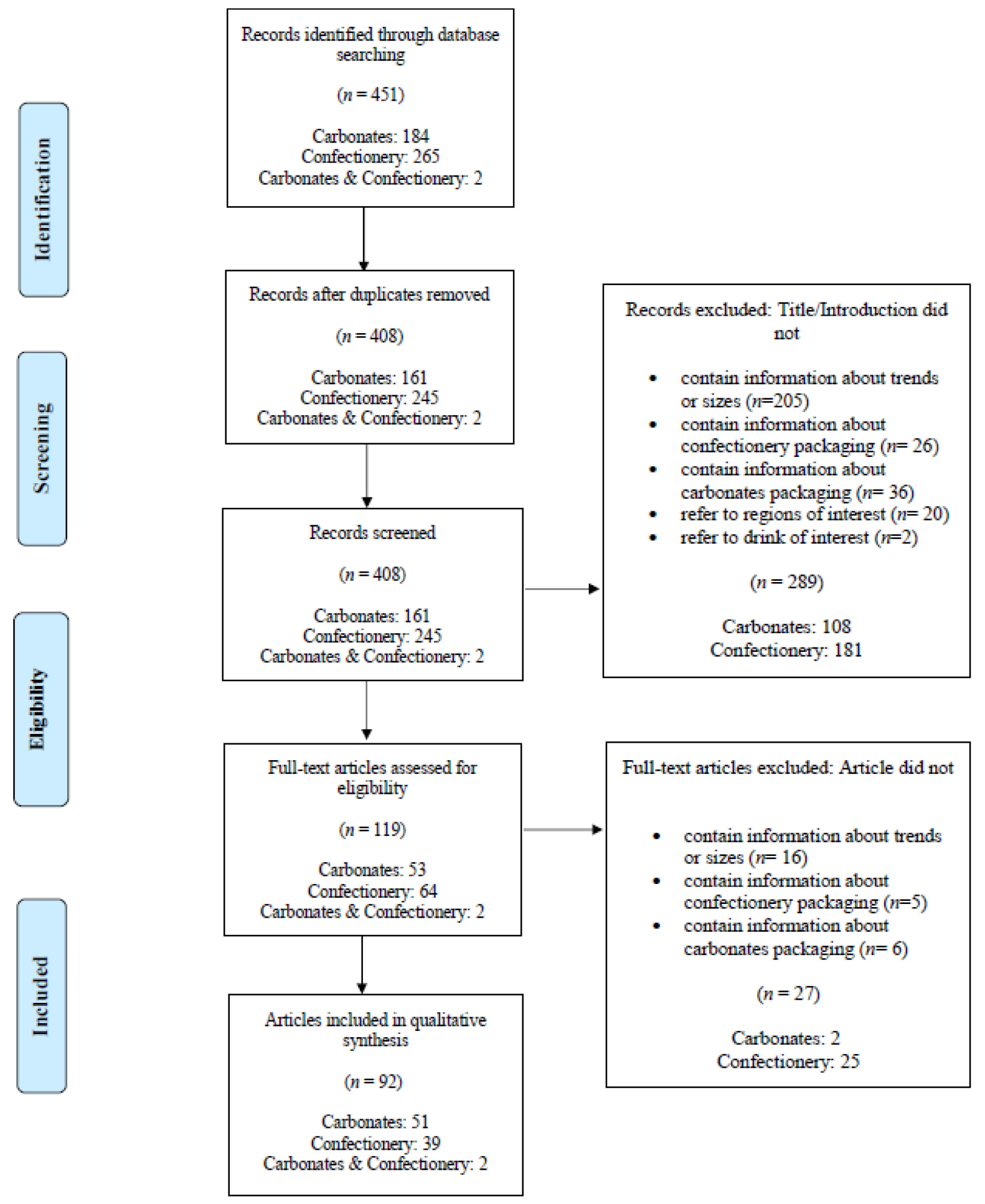

From: Moher D, Liberati A, Tetzlaff J, Altman DG, The PRISMA Group (2009). Preferred Reporting Items for Systematic Reviews and MetaAnalyses: The PRISMA Statement. PLoS Med 6(7): e1000097. doi:10.1371/joumal.pmed 1000097

For more information, visit www.prisma-statement_org

Figure 5. PRISMA flow chart of articles on carbonates and confectionery included in the scoping review.

\subsubsection{Carbonates}

All included studies $(n=53)$ were characterised according to the direction of package size change and the reason for this change as identified by industry (Table 1). For carbonates, 
46 publications identified a decrease, two studies identified an increase, and five found a mixture of increasing and decreasing package sizes (Table S3 for full details of articles). The main reasons reported for decreasing package sizes were increased consumer health consciousness $(n=30)$ regarding sugar and calorie content, convenience $(n=17)$, portion control $(n=14)$, market growth $(n=13)$, and innovation $(n=12)$. The reasons offered for increasing package sizes included value for money $(n=4)$, expanding product line $(n=2)$, market growth $(n=1)$, and demand from certain age groups $(n=1)$. This latter demand for larger sizes originated from 14-18 year old males in Australia [22].

Table 1. Industry reports on changes in carbonates package sizes.

\begin{tabular}{|c|c|c|}
\hline & Increase in Package Size & Decrease in Package Size \\
\hline \multicolumn{3}{|l|}{ Country $^{1}$} \\
\hline Australia & 4 & 12 \\
\hline USA & 3 & 27 \\
\hline UK & 2 & 19 \\
\hline Canada & 2 & 17 \\
\hline \multicolumn{3}{|l|}{ Year } \\
\hline 2005-2009 & 2 & 4 \\
\hline 2010-2014 & 2 & 14 \\
\hline $2015-2020$ & 3 & 3 \\
\hline \multicolumn{3}{|l|}{ Reason } \\
\hline Health consciousness & 0 & 30 \\
\hline Convenience & 0 & 17 \\
\hline Portion control & 0 & 14 \\
\hline Market growth & 1 & 13 \\
\hline Innovation & 0 & 12 \\
\hline Expanding product line & 2 & 11 \\
\hline Value for money & 4 & 9 \\
\hline Profit & 0 & 8 \\
\hline Small indulgence & 0 & 7 \\
\hline Sugar tax & 0 & 6 \\
\hline Premiumisation & 0 & 4 \\
\hline Impulse buying & 0 & 3 \\
\hline Manufacturing costs & 0 & 3 \\
\hline Age group & 1 & 3 \\
\hline Sharing trends & 0 & 1 \\
\hline
\end{tabular}

${ }^{1}$ Fourteen articles related to multiple countries.

\subsubsection{Confectionery}

Out of 41 articles on confectionery package sizes, 24 identified a decreasing trend, 7 found an increase, and 10 showed a mix of both (see Table 2 and Table S4 for full details of articles). The main reasons reported for reducing package sizes were portion control $(n=18)$, increased health consciousness of consumers $(n=16)$, allowance for small indulgences $(n=14)$, to reduce manufacturing costs $(n=10)$, and to increase affordability $(n=8)$ (Table 2). These reductions in package sizes were due to either small changes to the original package size or the introduction of new smaller pack/pouch sizes. Incremental reductions of $10-20 \%$ were reported in several articles [23-31]. The introduction of new smaller sizes was also reported, such as new Cadbury bars at $35 \mathrm{~g}$ and Hershey Sticks at 11 $\mathrm{g}(60$ calories) [32,33]. Some companies introduced portion-controlled package sizes and others introduced new high-end products, or premiumisation, reportedly as a response to consumers placing more value on quality rather than quantity. Some manufacturers have altered their larger single-serve confectionery bars (e.g., king size) into two or more smaller sizes while maintaining the overall weight of the product in an effort to prompt sharing, aid in portion control, and encourage impulse purchases.

Another trend observed in all countries was an increase in the release of larger sized packs, or 'share packs', (15 out of 16 articles reporting increases in package sizes concerned share packs), with sizes varying from $110-440 \mathrm{~g}$. The main reasons documented for this 
change by the food industry were a rise in sharing trends $(n=14)$ and value for money $(n=7)$. Additionally, a decrease in the size of confectionery pieces inside the larger share packs, known as 'miniaturisation' of countlines (or mini-bite-sized products), was noted, reportedly to further prompt sharing trends and aid in portion control.

Table 2. Industry reports on changes in confectionery package size.

\begin{tabular}{lcc}
\hline & Increase in Package Size & Decrease in Package Size \\
\hline Country & 2 & \\
Australia & 8 & 9 \\
USA & 11 & 11 \\
UK & 6 & 26 \\
Canada & & 10 \\
Year & 0 & \\
2005-2009 & 8 & 6 \\
2010-2014 & 8 & 5 \\
2015-2020 & & 24 \\
Reason & 14 & 8 \\
Sharing trends & 2 & 18 \\
Portion control & 0 & 16 \\
Health consciousness & 1 & 14 \\
Small indulgence & 7 & 8 \\
Value for money/affordability & 0 & 10 \\
Manufacturing costs & 4 & 5 \\
Convenience & 2 & 6 \\
Expanding product line & 2 & 4 \\
Profit & 2 & 3 \\
Innovation & 0 & 2 \\
Premiumisation & 0 & 1 \\
Impulse buying & & \\
1 Ten articles related to multiple countries. & & \\
&
\end{tabular}

\section{Discussion}

Using a systematic methodology, this study assessed the sales trends of carbonates and confectionery according to package size over a 15-year period along with industry perspectives on package size changes, in four high-income countries. Per capita unit sales data showed that consumers are increasing their purchases of smaller sized carbonates $(<300 \mathrm{~mL})$ and decreasing their purchases of larger sized carbonates $(\geq 2000 \mathrm{~mL})$. Industry reports mirrored this trend, citing consumer concerns over sugar and calorie content as reasons for the move towards smaller, portion-controlled sizes. However, unlike carbonates, confectionery sales data showed no consistent trends in package sizes across the selected countries over this time period. Sales of small package sizes $(<25 \mathrm{~g}$ and 25-49 g) decreased in Australia and Canada whereas larger package sizes ( $>100 \mathrm{~g})$ increased in Australia but remained relatively stable in the USA, Canada, and the UK. Industry reports described both decreases and increases in confectionery packaging for various reasons; single-serve confectionery sizes have gradually reduced in size, while larger share packs are gaining popularity.

An increased focus on reducing population sugar and energy intakes to curb obesity rates has led to increasing pressure on soft drink and confectionery manufacturers to act responsibly. Initiatives such as reformulation, public education campaigns, and the implementation of a tax on sugary drinks have been trialled and/or implemented in various countries. For example, in the UK, a Soft Drinks Industry Levy (SIDL) has been introduced, which is a two-tiered industry levy (5-8\% sugar content at $18 \mathrm{p} / \mathrm{L}$ and $>8 \%$ sugar content at $24 \mathrm{p} / \mathrm{L}$ ) intended to encourage reformulation, encourage a shift to lower sugar alternatives, and a reduction in package sizes [34]. This levy was an important reason for the decrease of carbonate package sizes reported by industry in our study. However, as the tax was introduced relatively recently, in 2018, we were unable to detect the impact on 
sales of smaller package sizes of carbonates. A UK study that compared carbonate sizes before and after the levy in leading/major supermarkets found that the SIDL led to an overall reduction of sugar in soft drinks, mostly due to reformulation, with little change in product size, with the exception of the small category of own-brand drinks [34]. There are currently no sugar taxes in Australia, Canada $[35,36]$, and much of the USA (with the exception of a few cities and districts) but all countries have implemented educational programs that encourage decreased consumption of SSBs in various populations. As consumers are progressively opting to purchase smaller sized carbonates, some of these initiatives may be having an impact.

The majority of the carbonate sales were retail sales, with only a small proportion from foodservice outlets, and our findings indicated a decrease in per capita unit sales of carbonates in foodservices in Australia, Canada, and the UK but not in the USA. However, in foodservices carbonates can be sold in packages (cans or bottles) or in cups using postmix dispensers. The latter measure is unavailable in the Euromonitor database. The most popular package sizes were similar for both retail and foodservice in Australia and Canada (300-399 mL) but differed in the USA (400-999 mL was more popular in foodservice) and the UK ( $<300 \mathrm{~mL}$ was more popular in foodservice). Reasons for these differences can only be speculated but are likely due to different target population and cultural expectations.

Public health initiatives, such as labelling and promoting healthier beverages, and price increases on sugary drinks in food outlets have shown some success in reducing sugar-sweetened beverage consumption [37]. A proposed ban on serving sizes greater than 16 ounces $(470 \mathrm{~mL})$ in New York foodservice establishments was not implemented due to beverage industry, business, and consumer opposition [38]. Altering portion sizes as a nudging intervention to reduce sugar-sweetened beverage consumption may be a more acceptable approach, although country-specific factors need to be considered, as one study found that consumers in the US may be more resistant than those in the UK [39]. Voluntary industry initiatives include the Balance Calories Initiative, which has led the top three American beverage companies to commit to promoting the use of smaller package sizes. An interim 2020 report found some growth among smaller containers of caloric beverages but this was offset by shifts from medium-sized to larger containers [40].

Confectionery sales data trends showed mixed results for package sizes by country. In Australia, growth in larger package sizes $(>100 \mathrm{~g})$, which typically include share packs, was observed. Industry reports confirmed that larger share packs of chocolates and sugar confectionery are gaining popularity. Resealable share packs are growing and are marketed as 'permissible snacking, encouraging consumers to share and enjoy the experience with friends and family'. Interestingly, it was found to be common for the size of individual confectionery portions within the larger sized share packs to decrease over time [41-44]. This was reportedly to 'help consumers with portion control, as these packs are a way for consumers to access portions smaller than the individually bought single-serve confectionery' [43]. Whilst these share packs have the potential to help consumers with portion control, there is currently little evidence to support this. A study that investigated how much of a 'portion-controlled', two-piece, king-size confectionery bar consumers would eat found that, despite the bar being portion controlled, consumers ate both pieces at one time [45].

In contrast to the growth in share packs, our review also found that manufacturers decreased the size of some single-serve confectionery packages. Incremental reductions of $10-20 \%$ were reported in several articles [23-31], exemplified by a Euromonitor analyst blog in 2015 that commented that Mars, Mondelez Hershey, and Nestlé had reduced the size of their countlines by $10-20 \%$, usually without reducing the unit price of the products [25]. This is commonly referred to as shrinkflation [24,25,27,28,43,44]. The most common reasons reported by the food industry for reducing confectionery package sizes were consumer health awareness, portion control, and allowing consumers 'to enjoy a permissible indulgence with less guilt', as well as to increase profit levels and achieve market growth [46-49]. However, the higher price per unit weight may deter consumers 
from purchasing these smaller sizes, as value for money is reportedly of great importance to consumers [23].

Several voluntary industry initiatives targeting confectionery have been implemented. In Australia and the UK, 'Be Treatwise', launched in 2006, aims to 'help consumers understand the role of confectionery as a treat food, and as a reminder to be responsible with portion sizes' [50]. In the USA and Canada, 'Always A Treat' aims to provide clear calorie labelling and more choice in smaller packages [51]. Neither of these initiatives was identified as part of the scoping review and their effectiveness is yet to be determined, with our review finding no evidence of increased sales of smaller confectionery packs over the past 15 years.

This study included a variety of data sources, qualitative and quantitative, and investigated a range of databases which provided good coverage of food industry interests in changing package sizes. The selected countries were large, high-income countries and therefore the trends found represent a large proportion of the developed world. All data were double screened, allowing for greater quality and reliability of results. Although the study provided good coverage of data for each of the countries, only a few industry articles were published between 2005 and 2019 in the Euromonitor and IBIS databases and Google search engine. Limitations of the study included the lack of separation of sugar-sweetened versus intensely-sweetened beverages in the Euromonitor sales data by package size; the fact that confectionery sales from foodservice outlets were unavailable; and the inability to distinguish between sales of share packs and chocolate bars, as both were all categorised in the $\geq 100 \mathrm{~g}$ size band. Additionally, limited data were available on the consumer characteristics of those purchasing smaller versus larger package sizes. The package sizes used in our analysis were summarized as band widths and using individual package sizes may detect more subtle changes over time.

\section{Conclusions}

Monitoring package sizes of discretionary foods and beverages, and recognising the reasons for modifying, and particularly downsizing, package sizes, is important to improve the food supply, assist consumers in eating healthier diets, and reduce levels of overweight and obesity. Our study presents a novel insight regarding sales trends of discretionary food package sizes, finding growth in smaller package sizes in carbonates but more diverse findings for confectionery. Promisingly, health consciousness was found to be the primary driver for reductions in both confectionary and SSBs. However, the food industry is also motivated to increase profitability and employs a variety of strategies, such as using both larger and smaller package sizes, to increase sales to consumers who are motivated by factors other than health, such as value for money. As smaller packages also drive sales and potentially allow new indulgences that may not have occurred with larger sizes perceived to be unhealthy, further research into potential unintended risks associated with consumption of smaller package sizes is warranted.

Supplementary Materials: The following are available online at https:/ / www.mdpi.com/article/10 .3390 / foods10051071/s1, Figure S1: Search strategy and terms for sales data and qualitative data for carbonates and confectionery using the Euromonitor database, Figure S2: Retail unit volume sales per capita in carbonates according to package size band in (A) Australia, (B) the USA, (C) Canada, and (D) the UK. Figure S3: Foodservice unit volume sales per capita in carbonates according to package size band in (A) Australia, (B) the USA, (C) Canada, and (D) the UK, Table S1: Search strategy for Google search 1, Table S2: Definitions for retail sales and food service sales used by Euromonitor, Table S3: Search results for industry reasons for changes in package sizes for carbonates, Table S4. Search results for industry reasons for changes in package sizes for confectionery [52-120].

Author Contributions: Conceptualization and methodology, A.G. and A.R.; data curation, C.J. and K.F. and A.R.; writing — original draft preparation, C.J. and K.F.; writing—review and editing, A.G. and A.R.; supervision, A.G. and A.R. All authors have read and agreed to the published version of the manuscript. 
Funding: This research received no external funding.

Institutional Review Board Statement: Not applicable.

Informed Consent Statement: Not applicable.

Data Availability Statement: Not applicable.

Acknowledgments: We would like to acknowledge the help of the liaison librarians Monica Cooper and Emma Petherbridge.

Conflicts of Interest: The authors declare no conflict of interest.

\section{References}

1. Zheng, M.; Rangan, A.; Meertens, B.; Wu, J.H.Y. Changes in Typical Portion Sizes of Commonly Consumed Discretionary Foods among Australian Adults from 1995 to 2011-2012. Nutrients 2017, 9, 577. [CrossRef] [PubMed]

2. Smiciklas-Wright, H.; Mickle, S.J.; Goldman, J.D.; Cook, A. Foods commonly eaten in the United States, 1989-1991 and 1994-1996: Are portion sizes changing? J. Am. Diet. Assoc. 2003, 103, 41-47. [CrossRef] [PubMed]

3. Hollands, G.J.; Marteau, T.M.; Jebb, S.A.; Lewis, H.B.; Wei, Y.; Higgins, J.P.T.; Ogilvie, D. Portion, package or tableware size for changing selection and consumption of food, alcohol and tobacco. Cochrane Database Syst. Rev. 2015. [CrossRef] [PubMed]

4. Zlatevska, N.; Holden, S.S. Sizing up the effect of portion size on consumption: A meta-analytic review. J. Mark. 2014, 78, 140-154. [CrossRef]

5. Steenhuis, I.P.M. Portion Size: Latest Developments and Interventions. Curr. Obes. Rep. 2017, 6, 10-17. [CrossRef] [PubMed]

6. World Health Organization; Food and Agriculture Organization. Diet, Nutrition and the Prevention of Chronic Diseases; WHO Technical Report Series 916; WHO: Geneva, Switzerland, 2003.

7. Sui, Z.W.W.; Louie, J.C.; Rangan, A. Discretionary food and beverage consumption and its association with demographic characteristics, weight status, and fruit and vegetable intakes in Australian adults. Public Health Nutr. 2017, $20,274-281$. [CrossRef] [PubMed]

8. Australian Bureau of Statistics. Australian Health Survey: Nutrition First Results—Food and Nutrients, 2011-2012. Available online: https:/ / www.ausstats.abs.gov.au/Ausstats/subscriber.nsf/0/4683FD7315DFDFDBCA257D080014F9E0/\$File/australian\% 20health\%20survey\%20nutrition\%20first\%20results\%20-\%20food\%20and\%20nutrients,\%202011-12.pdf (accessed on 11 March 2020).

9. Wartella, E.A.; Boon, C.S. Front-of-Package Nutrition Rating Systems and Symbols: Phase I Report; National Academies Press: Cambridge, MA, USA, 2010.

10. Roberts, C.; Maplethorpe, N.; Cox, L.; Meadows, S.; Nicholson, S.; Page, P.; Swan, G. National Diet and Nutrition Survey: Results from Years 7 and 8 (Combined) of the Rolling Programme (2014/2015 to 2015/2016); Public Health England: London, UK, 2018.

11. Jones, A.C.; Hammond, D. Beverage consumption and energy intake among Canadians: Analyses of 2004 and 2015 national dietary intake data. Nutr. J. 2019, 18, 60. [CrossRef] [PubMed]

12. Lewis, M.L.A. Effective Portion Size Strategies. An evidence Review Prepared for the Australian Department of Health on Behalf of the Australian Prevention Partnership Centre; The Australian Prevention Partnership Centre: Sydney, NSW, Australia, 2017.

13. Crino, M.; Sacks, G.; Wu, J.H.Y. A Review of Population-Level Actions Targeting Reductions in Food Portion Sizes to Address Obesity and Related Non-communicable Diseases. Curr. Nutr. Rep. 2016, 5, 323-332. [CrossRef]

14. Almiron-Roig, E.; Hollands, G.J.; Vargas, M.Á.; Brunstrom, J.M. A review of evidence supporting current strategies, challenges, and opportunities to reduce portion sizes. Nutr. Rev. 2019, 78, 91-114. [CrossRef] [PubMed]

15. Mattes, R.D. Evidence on the "normalizing" effect of reducing food-portion sizes. Am. J. Clin. Nutr. 2018, 107, 501-503. [CrossRef] [PubMed]

16. Robinson, E.K.I. Portion size and later food intake: Evidence on the "normalizing" effect of reducing food portion sizes. Am. J. Clin. Nutr. 2018, 107, 640-646. [CrossRef] [PubMed]

17. Robinson, E.H.J.; Keenan, G.S.; Kersbergen, I. When a portion becomes a norm: Exposure to a smaller vs. larger portion of food affects later food intake. Food Qual. Prefer. 2019, 75, 113-117. [CrossRef] [PubMed]

18. Passport Global Market Information Database; Euromonitor International: London, UK, 2019.

19. Tricco, A.C.; Lillie, E.; Zarin, W.; O’Brien, K.K.; Colquhoun, H.; Levac, D.; Moher, D.; Peters, M.D.J.; Horsley, T.; Weeks, L.; et al. PRISMA Extension for Scoping Reviews (PRISMAScR): Checklist and Explanation. Ann. Intern. Med 2018, 169, 467-473. [CrossRef] [PubMed]

20. IBISWorld AU: Market Research Reports and Analysis; IBISWorld Australia: Melbourne, VIC, Australia, 2020.

21. Dumas, A.A.; Desroches, S. Users, Uses, and Effects of Social Media in Dietetic Practice: Scoping Review of the Quantitative and Qualitative Evidence. J. Med. Internet Res. 2018, 20, 55. [CrossRef] [PubMed]

22. Tower, P. Fizzy Drinks Losing Their Sparkle. Available online: https://insidefmcg.com.au/2017/01/06/fizzy-drinks-losingtheir-sparkle/ (accessed on 3 March 2020). 
23. Euromonitor International. Affordability is Key in Global Food Packaging; Euromonitor International: London, UK, 2015.

24. Brown, D.; Bryson, M.; Keast, L. Biscuits and Chocolates Take the 'Shrinkflation' Test. Available online: https://www.bbc.com/ news/uk-42864685 (accessed on 11 April 2020).

25. Skelly, J. A Bittersweet Future for Sugar Consumption in Packaged Food; Euromonitor International: London, UK, 2015.

26. Brook, B. Cadbury to Reduce the Size of Its Chocolate Blocks. Available online: https://www.news.com.au/finance/business/retail/ cadbury-to-reduce-the-size-of-its-chocolate-bars/news-story/601eca5010a1d2ef91ea3bdc0689886a (accessed on 11 April 2020).

27. Dussimon, K. Global Snacks Packaging: Staying Relevant Through Pack Sizing Strategies; Euromonitor International: London, UK, 2018.

28. Wood, Z.S.B. Jaffa Cakes Packet Size Reduced in Latest 'Shrinkflation' Move. Available online: https:/ /www.theguardian.com/ business/2017/sep/26/jaffa-cakes-pack-size-cut-shrinkflation-mcvities-cadbury (accessed on 11 April 2020).

29. Yu, D. Mars Admits Shrinking Maltesers and Galaxy Counter Packs was 'Difficult Decision'. Available online: https://www. confectionerynews.com/Article/2016/11/22/Mars-shrinks-Maltesers-and-Galaxy-Counters-packs (accessed on 11 April 2020).

30. Kollmorgen, A. Shrinking Pack Sizes. Available online: https://www.choice.com.au/shopping/packaging-labelling-andadvertising/packaging/articles/shrinking-pack-sizes-081715 (accessed on 11 April 2020).

31. Dussimon, K. Sizing Strategies in Global Food Packaging: Smaller Packs for Higher Value; Euromonitor International: London, UK, 2016.

32. Contributor. Cadbury Extends Darkmilk Range with New Pack Size and Flavour. Available online: https://www.foodbev.com/ news / cadbury-extends-darkmilk-range-with-new-pack-size-and-flavour /?_cf_chl_jschl_tk_=cd133519050d1e29e8dd750 3883f8e6208edc293-1586590274-0-AbfG6A3tkP9isCzJ3rxvMTCzIzg39Cx9Q9H2WtsYxWMmnPC5OfSVjAvSCT9SN5fmVIi_ 1QeX56EAh6gHuVBGLyCldx30Kj72kFGgVdPKDmhLfYzcLH8qYpKetZxTxmWzba4Fud4PU5EkIdnbFhwsB0_AZ4w10y3r9 nG0Dh94VR7bw_nDqCI0ICyAGWwiVs75hkq4LeD6VbZ2c3kWIjrmkudJWzXaVtCY1ChSQQhlfqIoOVXtuM8nDAqzwx8 dYtPzRywbsu7uM1ob0wr2D1V7CzKR9QkEJCC_NtimY_KMNdNzDSV-izHPe3nVLLOcmfrsdpNjCSSZBMSYfBETm9 XdoggZpPOf1EsI66nk_JEG3LnU (accessed on 11 April 2020).

33. Euromonitor International. Minisize Me: Portion Control as the New Path to Healthy Eating; Euromonitor International: London, UK, 2006.

34. Scarborough, P.; Adhikari, V.; Harrington, R.A.; Elhussein, A.; Briggs, A.; Rayner, M.; Adams, J.; Cummins, S.; Penney, T.; White, M. Impact of the announcement and implementation of the UK Soft Drinks Industry Levy on sugar content, price, product size and number of available soft drinks in the UK, 2015-19: A controlled interrupted time series analysis. PLoS Med. 2020, 17, e1003025. [CrossRef] [PubMed]

35. Ogilvie, K.K. Obesity in Canada: Report of the Standing Senate Committee on Social Affairs, Science and Technology; The Senate of Canada: Ottawa, ON, Canada, 2016.

36. Di Natale, R.L.S.; Georgiou, P.; Singh, L.; Kitching, K.; Paterson, J.; Stoker, A.; Storer, T.; Bilyk, C.; Brockman, S.; Brown, C.; et al. Select Committee into the Obesity Epidemic in Australia; Parliament of Australia: Canberra, Australia, 2018.

37. Von Philipsborn, P.S.J.M.; Burns, J.; Busert, L.K.; Pfadenhauer, L.M.; Polus, S.; Holzapfel, C.; Hauner, H.; Rehfuess, E. Environmental interventions to reduce the consumption of sugar-sweetened beverages and their effects on health. Cochrane Databse Syst. Rev. 2019, 6, CD012292. [CrossRef] [PubMed]

38. Roberto, C.A. Public Health and Legal Arguments in Favor of a Policy to Cap the Portion Sizes of Sugar-Sweetened Beverages. Am. J. Public Health 2015, 105, 2183-2190. [CrossRef] [PubMed]

39. Petrescu, D.C.; Couturier, D.L.; Ng, Y.L.; Marteau, T.M. Public Acceptability in the UK and USA of Nudging to Reduce Obesity: The Example of Reducing Sugar-Sweetened Beverages Consumption. PLoS ONE 2016, 11, e0155995. [CrossRef] [PubMed]

40. Keybridge. 2025 Beverage Calories Initiative: Report on 2019 Progress toward the National Calorie Goal. September 2020. Available online: https:/ / aba-bigtree.s3.amazonaws.com/files/resources/bic-2019-national-progress-report.pdf (accessed on 3 May 2021).

41. Euromonitor International. Chocolate Confectionery in the United Kingdom; Euromonitor International: London, UK, 2019.

42. Hosafci, P. Confectionery in Western Europe. Available online: https:/ / go.euromonitor.com/passport.html (accessed on 18 May 2020).

43. Hudak, M. Five Trends in Snacks from the Sweets and Snacks Expo 2014; Euromonitor International: London, UK, 2014.

44. Bandy, L. Guilt-Free Snacking? How Share Bags are Contributing to Confectionery Growth; Euromonitor International: London, UK, 2014.

45. Vermeer, W.M.; Steenhuis, I.H. Two pack king size chocolate bars. Can we manage our consumption? Appetite 2010, 54, 414-417. [CrossRef] [PubMed]

46. Euromonitor International. Global Food Packaging: Nurturing Future Sales Growth Through Innovation; Euromonitor International: London, UK, 2014.

47. Dussimon, K. Manufacturers Look to Packaging to Up Impulse Purchase of Miniaturised Foods; Euromonitor International: London, UK, 2013.

48. Euromonitor International. Confectionery Packaging in the US; Euromonitor International: London, UK, 2019.

49. Dussimon, K. Pack Downsizing Strategy to Meet Snacking Demand-Flexibles Show the Way; Euromonitor International: London, UK, 2015. 
50. AiGroup. Be Treatwise: Enjoy a Balanced Diet. Available online: http://www.betreatwise.info/ (accessed on 18 May 2020).

51. National Confectioners Association. Always a Treat. Available online: https://alwaysatreat.com/ (accessed on 18 May 2020).

52. Hector, D.; Rangan, A.; Louie, J.; Flood, V.; Gill, T. Soft Drinks, Weight Status and Health: A Review. Available online: https://www.health.nsw.gov.au/heal/Publications/soft-drinks-report.pdf (accessed on 13 April 2020).

53. Jones, S. Coca-Cola Identifies 'Portion Control' Among Reasons for Downsizing of 450mL Bottle. Available online: https: / / mumbrella.com.au/coca-cola-identifies-portion-control-among-reasons-for-downsizing-of-450ml-bottle-320390 (accessed on 3 March 2020).

54. The Sydney Morning Herald. Coca-Cola's Smaller Cans May Make US Drink More. Available online: https://www.smh.com.au/ business / companies / cocacolas-smaller-cans-may-make-us-drink-more-20160212-gms1ow.html (accessed on 6 March 2020).

55. Black, C. Coca-Cola Australia Submission-Select Committee Inquiry into the Obesity Epidemic in Australia. Available online: https://www.aph.gov.au/Parliamentary_Business/Committees/Senate/Obesity_epidemic_in_Australia/Obesity/ \{\}/ media/Committees/Obesity_epidemic_in_Australia/Report/report.pdf (accessed on 11 April 2020).

56. Chung, F. Big Change Coming to Pepsi, Coke. Available online: https://www.dailymercury.com.au/news/soft-drink-makerspledge-to-cut-sugar-20-per-cent-/3450976/ (accessed on 3 March 2020).

57. The Coca-Cola Company. Coca-Cola in Australia Commits to Reducing Sugar by 20\% by 2025 along with Beverages Industry. Available online: https://www.coca-colacompany.com/au/media-centre/media-releases/coca-cola-in-australia-reducingsugar-by-20-per-cent-by-2025-beverages-industry (accessed on 4 March 2020).

58. Koronios, E. Global Soft Drink \& Bottled Water Manufacturing; IBISWorld Australia: Melbourne, VIC, Australia, 2019.

59. Vuong, B. Soft Drink and Pre-Packaged Food Wholesaling in Australia; IBISWorld Australia: Melbourne, VIC, Australia, 2019.

60. Euromonitor International. Soft Drinks Packaging in Australia; Euromonitor International: London, UK, 2020.

61. Euromonitor International. Packaging Innovations Shape Soft Drinks Industry; Euromonitor International: London, UK, 2005.

62. Punchard, B. Shrinking Pack Sizes as Consumers Choose Quality Over Quantity; Euromonitor International: London UK, 2009.

63. Dussimon, K. Make Yourself Feel at Home... Through Packaging; Euromonitor International: London, UK, 2010.

64. Telford, H. A 12 oz Indulgence: Can Glass Counter Dwindling CSD Consumption in the US? Euromonitor International: London, $\mathrm{UK}, 2013$.

65. Telford, H. Sweets \& Soda: Can Carbonates Learn a Lesson from US Confectionery? Euromonitor International: London, UK, 2014.

66. Maddock, J. Shrinking Packs: One Answer to Concerns over Carbonates and Expanding Waistlines; Euromonitor International: London, UK, 2014.

67. Holtz, S. Mini Cans Bring Major Benefits to Coca-Cola Co., PepsiCo. Available online: https://www.cspdailynews.com/ beverages / mini-cans-bring-major-benefits-coca-cola-co-pepsico (accessed on 6 March 2020).

68. Wahba, P. Big 3 Soda Makers Pledge to Cut Drink Calorie Consumption by 20\% by 2025. Available online: https://fortune.com/ 2014/09/23/coke-pepsi-snapple-sugar/ (accessed on 6 March 2020).

69. Wong, V. Coca-Cola Says Its Mini Cans Are “Reinventing” The Soda Business. Available online: https: / /www.buzzfeednews. com/article/venessawong/coca-cola-says-its-mini-cans-are-reinventing-the-soda-busine (accessed on 6 March 2020).

70. Tuttle, B. How Coke Convinced Us to Pay More ... for Less Soda. Available online: https://money.com/mini-coke-cans-trendvalue-price/ (accessed on 6 March 2020).

71. Ferdman, R.A. Coca-Cola's Clever New Trick. Available online: https://www.washingtonpost.com/news/wonk/wp/2016/02/ 11/ coca-colas-clever-little-trick / (accessed on 3 March 2020).

72. The Coca-Cola Company. I Heard The Coca-Cola Company Offers Smaller Package Sizes. Can You Tell Me More? Available online: https:/ / www.coca-colaproductfacts.com/en/faq/packaging/mini-soda-cans-for-portion-control/ (accessed on 4 March 2020).

73. CNBC. Coke Shares Pop Ahead of One of 'Most Promising' New Launches in Decades. Available online: https://www.cnbc. com/2019/10/18/coke-shares-pop-ahead-of-one-of-most-promising-new-launch-in-decades.html (accessed on 3 March 2020).

74. Banoub, N.; Hillyar, K. Coca-Cola Canada Kicks off Exciting Year of Innovation With New Mini Bottle. Available online: https:/ / business.financialpost.com/pmn/press-releases-pmn/business-wire-news-releases-pmn/coca-cola-canada-kicks-offexciting-year-of-innovation-with-new-mini-bottle (accessed on 3 March 2020).

75. Beverage Industry. Coca-Cola Mini Bottles Enter Canadian Market. Available online: https://www.bevindustry.com/articles/91 966-coca-cola-mini-bottles-enter-canadian-market (accessed on 4 March 2020).

76. Euromonitor International. Soft Drinks Packaging in Canada; Euromonitor International: London, UK, 2020.

77. Dussimon, K. 2010: A Turning Point for Beverage Cans in Europe; Euromonitor International: London, UK, 2011.

78. Euromonitor International. Beverage Cans Help Brand Owners Boost Sales Through Innovation; Euromonitor International: London, UK, 2013.

79. Dussimon, K. Metal Beverage Can Proves Versatile in the Global Beverages Arena; Euromonitor International: London, UK, 2013.

80. Dussimon, K. Better than Packaging that Speaks to Consumers? Packaging that Speaks to You. Euromonitor International:: London, UK, 2015.

81. Euromonitor International. Western European Beverage Packaging at a Standstill; Euromonitor International: London, UK, 2015.

82. Arthur, R. Good Things Come in Small Packages: The Growth of Smaller Packaging Formats. Available online: https://www. beveragedaily.com/Article/2018/11/26/Good-things-come-in-small-packages-The-growth-of-smaller-packaging-formats (accessed on 4 March 2020). 
83. BBC News. Coca-Cola to Cut Bottle Size But Increase Price in Face of Sugar Tax. Available online: https://www.bbc.com/news / health-42690487 (accessed on 4 March 2020).

84. Coca-Cola Great Britain. The Sugar Tax. Available online: https://www.coca-cola.co.uk/ingredients/reducing-sugar/lets-talkabout-soft-drinks-tax (accessed on 4 March 2020).

85. Graham, P. Convenience \& Impulse Soft Drinks Review 2018. Available online: https://www.britvic.com/ \{\}/media/Files/B/ Britvic-V3/documents/pdf/sdr-convenience-and-impulse-cover-2018-v1.pdf (accessed on 11 April 2020).

86. Wood, Z. Coca-Cola to Sell Smaller Bottles at Higher Prices in Response to Sugar Tax. Available online: https://www.theguardian. com/society/2018/jan/05/coca-cola-to-sell-smaller-bottles-at-higher-prices-in-response-to-sugar-tax (accessed on 4 March 2020).

87. Euromonitor International. Soft Drinks Packaging in United Kingdom; Euromonitor International: London, UK, 2020.

88. Metal Packaging Europe. Which Beverage Can Sizes Do Europeans Prefer? Available online: https://www.metalpackagingeurope. org/article/which-beverage-can-sizes-do-europeans-prefer (accessed on 6 March 2020).

89. Downey, R. Convenience And Portability Drive North American Beverage Packaging Innovation; Euromonitor International: London, UK, 2009.

90. Williams, J.D.; Goldsworthy, P. Breaking Down the Chain: A Guide to the Soft Drink Industry. Available online: https: //www.foodpolitics.com/wp-content/uploads/SoftDrinkIndustryMarketing_11.pdf (accessed on 11 March 2020).

91. Maiseviciute, R. Carbonates in the US: Is There a Threat to Packaging? Euromonitor International: London, UK, 2013.

92. Trefis Team. Could Smaller Servings Boost Margins for Coca-Cola and Pepsi, Amid Soda Slowdown? Available online: https: / / www.forbes.com/sites / greatspeculations/2014/08/06/could-smaller-servings-boost-margins-for-coca-cola-andpepsi-amid-soda-slowdown/\#22bd437f6489 (accessed on 6 March 2020).

93. Packaging Converting \& Intellegence. Trends in the Carbonated Soft Drinks Market. Available online: http://www.pci-mag. com/features/featuretrends-in-the-carbonated-soft-drinks-market-4775235/ (accessed on 4 March 2020).

94. Morton, A. Consumers Driving Shift to Smaller Pack Sizes-PepsiCo CEO. Available online: https://www.just-drinks.com/ news / consumers-driving-shift-to-smaller-pack-sizes-pepsico-ceo_id129451.aspx (accessed on 4 March 2020).

95. The Coca-Cola Company. How Much Sugar is in Coca-Cola? Available online: https://www.coca-colacompany.com/faqs/howmuch-sugar-is-in-coca-cola (accessed on 4 March 2020).

96. Dussimon, K. Carbonates in Multipacks—The Battle between Enclosed Cartons and Shrink Wrap; Euromonitor International: London, UK, 2009.

97. Downey, R. Falling Carbonate Sales Stalls Beverage Can Position; Euromonitor International: London, UK, 2011.

98. Dussimon, K. New Global Briefing: Beverage Growth Supported by Refreshing Packaging Developments; Euromonitor International: London, UK, 2014.

99. Almeda, S. How Can Packaging Innovation Support Health Trends in Soft Drinks? Almeda, S., Ed.; Euromonitor International: London, UK, 2017.

100. Punchard, B. What's Happening in Soft Drinks Packaging; Euromonitor International: London, UK, 2009.

101. Bandy, L. Where Are Our Calories Coming From? Actions Being Taken to Improve Nutrition; Euromonitor International: London, UK, 2015.

102. Downey, R. Smaller is Better as Global Packaging Growth is Shaped by Variation in Pack Sizes; Euromonitor International: London, UK, 2016.

103. Downey, R. How the Healthy Living Trend is Shaping Consumers' Packaging Choices; Euromonitor International: London, UK, 2019.

104. Nestle. Frequently Asked Questions: Allen's Lollies. Available online: https:/ /www.allenslollies.com.au/faq (accessed on 11 April 2020).

105. Vuong, B. Chocolate and Confectionery Manufacturing in Australia; IBISWorld Australia: Melbourne, VIC, Australia, 11 April 2019.

106. Euromonitor International. Chocolate Confectionery in Australia; Euromonitor International: London, UK, 2019.

107. Euromonitor International. Confectionery Packaging in Australia; Euromonitor International: London, UK, 2020.

108. Euromonitor International. Confectionery Packaging in Canada; Euromonitor International: London, UK, 2020.

109. Euromonitor International. Cadbury Fights Obesity with Portion Control; Euromonitor International: London, UK, 2005.

110. Dussimon, K. Window of Opportunity for Confectionery and Bakery Packaging in Europe; Euromonitor International: London, UK, 2015.

111. Polat, E. Chocolate Confectionery in Western Europe; Euromonitor International: London, UK, 2019.

112. Euromonitor International. Confectionery Packaging in the United Kingdom; Euromonitor International: London, UK, 2020.

113. Dussimon, K. "Share Packs" Give Value for Money its True Meaning in Snacking Products; Euromonitor International: London, UK, 2015.

114. Bandy, L. Global Confectionery Overview: Key Categories, Countries and Trends to 2019; Euromonitor International: London, UK, 2014.

115. Euromonitor International. Extensive Sizing Options Ensure Flexibles Succeed in Confectionery; Euromonitor International: London, UK, 2014.

116. Euromonitor International. The Good, the Bad, and the Ugly: Assessing Sugar Confectionery; Euromonitor International: London, UK, 2015.

117. Euromonitor International. 2015 a Solid Year for Packaging, Retail Volumes Reach 3.35 Trillion Units; Euromonitor International: London, UK, 2016. 
118. Wikipedia. Mars (Chocolate Bar). Available online: https://en.wikipedia.org/wiki/Mars_(chocolate_bar) (accessed on 11 April 2020).

119. Euromonitor International. Global Packaged Food: Driving Confectionery Retail Values in an Uncertain Economic Climate; Euromonitor International: London, UK, 2009.

120. Dussimon, K. Global Chocolate Confectionery: Permitting Indulgence Again; Euromonitor International: London, UK, 2019. 